\title{
Rethinking the Structure of Student Recruitment and Efforts to Increase Racial and Ethnic Diversity in Doctoral Education
}

\author{
Kimberly A. Griffin \\ University of Maryland, College \\ Park, MD, United States
}

\author{
Marcela Muñiz \\ Harvard University, Cambridge, \\ MA, United States
}

kgriff29@umd.edu

\section{marcela.muniz@gmail.com}

\section{Abstract}

While researchers, institutional leaders, and policymakers have made significant progress towards increasing undergraduate student diversity in the United States, diversity in graduate education has been less often studied and a more challenging goal on which to make progress. This qualitative study explores the roles and work of graduate diversity officers (GDOs) in student recruitment activities with a focus on how race and issues of diversity manifest and influence this process. Interviews with fourteen GDOs at 11 different research universities in the United States highlight the phases in the graduate recruitment process, the manner in which diversity is considered at each stage, and GDOs' perceptions of their ability to shape this process. Findings suggest that GDOs are important institutional agents in diversification efforts; however, faculty engagement and broad institutional commitment are required to increase diversity in graduate education due to GDOs' often limited involvement in the admissions stage of the recruitment process, where race becomes the most salient in decision making.

Keywords: diversity, recruitment, administration, graduate education, United States

\section{Introduction}

Given demographic shifts in the United States over the past few decades, the population of students entering higher education will be increasingly diverse. However, multiple challenges and barriers have been identified which limit the translation of this diversity to graduate programs, and African American, Latino, and Native American students remain underrepresented in graduate education (Council of Graduate Schools and Educational Testing Service, 2010). The lack of racial and ethnic diversity in graduate education in the United States has widely been identified as problematic (e.g., Council of Graduate Schools, 2009; Tierney, Campbell, \& Sanchez, 2004);

Material published as part of this publication, either on-line or in print, is copyrighted by the Informing Science Institute. Permission to make digital or paper copy of part or all of these works for personal or classroom use is granted without fee provided that the copies are not made or distributed for profit or commercial advantage AND that copies 1) bear this notice in full and 2) give the full citation on the first page. It is permissible to abstract these works so long as credit is given. To copy in all other cases or to republish or to post on a server or to redistribute to lists requires specific permission and payment of a fee. Contact Publisher@InformingScience.org to request redistribution permission. however, empirical work informing efforts to promote change is limited. Specifically, there is little understanding of the process by which African American, Asian American/Pacific Islander, Latina/o, and Native American students are recruited into and encouraged to pursue doctoral programs generally or at specific institutions. 
While some researchers have conducted institutional self-studies or documented their scholarly reflections on recruitment strategies to increase graduate diversity (e.g., Aspray \& Bernat, 2000; Olson, 1988; Pruitt \& Isaac, 1985; Tierney et al., 2004), empirically based studies addressing recruitment are relatively absent from the literature. The limited literature focusing on graduate student recruitment has largely focused on the factors which shape students' enrollment decisions; however, recruitment goes beyond enrollment. Within the context of this study, recruitment is understood as including efforts institutions in the United States make to encourage application (outreach), admissions, and the ultimate decision to enroll (yield).

This study focuses on administrators' perceptions and engagement in the process of implementing various diversity recruitment strategies in graduate education. Rather than identifying which strategies are more or less effective (Griffin \& Muniz, 2011) or the influence of internal and external factors on diversity recruitment strategies (Griffin, Muniz, \& Espinsoa, 2012), this study focuses on defining the recruitment process itself and understanding how diversity is considered within that process. Better understanding of the nuances of the recruitment process, including the challenges and opportunities for influence, is important to promoting greater success as institutions in the United States seek to increase diversity in their graduate student communities.

While faculty have traditionally been charged with recruitment work within the United States system of graduate education due to its decentralized nature (Gumport, 1993; Posselt, 2013), they may not be fully engaged in all of the dimensions of the recruitment process. Student outreach has little connection to traditional faculty reward structures, which emphasize scholarly productivity over student contact, teaching, or service (Tierney \& Bensimon, 1996). These factors may make the time intensive process associated with graduate student recruitment, particularly outreach, unappealing to faculty, creating a need for institutions to hire professional administrators to meet diversity goals. Thus, this research addresses the work done by a group of administrators charged with increasing diversity within the graduate student community: Graduate Diversity Officers (GDOs).

Within the context of this study, we define GDOs as the individuals charged with improving the diversity of the graduate student population on their respective campuses, largely through the recruitment and/or retention of those from underrepresented communities. Their titles often vary and graduate student diversity may not be their sole responsibility; however, individuals who identify as GDOs focus on the recruitment and retention of graduate students from underrepresented or underserved populations as a central part of their work. The work, responsibilities, roles, and effectiveness of these administrators have gone unstudied; yet, as those who may be most directly working on initiatives to increase graduate student diversity, GDOs have a valuable insider's view of the ways in which colleges and universities are challenged and successful in their efforts. Further, deeper knowledge on the perspective of administrators implementing diversity recruitment strategies facilitates understandings of the challenges and multiple considerations associated with increasing the number of underrepresented minorities in graduate education.

The purpose of this study is both to explore the role race plays in the graduate student recruitment process and how GDOs perceive their influence on efforts to promote diversity. Based on data collected from 14 GDOs, we develop and present a model of graduate student recruitment within a United States context, particularly attending to the ways in which racial diversity is considered and influences each stage of the process. Participant narratives suggest race and diversity play prominent roles in this process, particularly manifested in the ways in which the qualifications of students of color are perceived, which can ultimately limit efforts to increase graduate diversity. GDOs aim to address these challenges, acknowledging the salience of race at various stages of the recruitment process, and implementing a distinctive set of strategies to overcome barriers within the stages in which they perceive themselves as having the greatest influence. 


\section{Background}

\section{Recruitment in Graduate Education}

An exploration of how issues related to race and diversity can manifest and influence the graduate recruitment process requires an examination of previous literature on this topic. The majority of the literature on higher education recruitment in the United States focuses on undergraduate students. Much of the extant literature on graduate student recruitment can be grouped into three categories, and is organized accordingly below. The first category is composed of articles addressing institutional outreach, or efforts to encourage students to apply to graduate school generally or a specific institution. The second category focuses on admissions policies and practices. The third category addresses yield activities, or strategies to draw students to a specific institution after being admitted.

\section{Outreach}

There is a small number of journal articles and reports attending specifically to diversity and outreach at the graduate level, which are largely based on anecdotal evidence and document "best practices" identified by practitioners engaged in this work (e.g., Aspray \& Bernat, 2000; Olson, 1988; Tierney et al., 2004). Institutional leaders and faculty are urged to take advantage of the changing demographics in American society and make extra efforts to encourage students from traditionally underrepresented groups to consider attending graduate school broadly, and their respective institutions in particular (Aspray \& Bernat, 2000). Suggested strategies include incorporation of innovative undergraduate curricula that highlight problem solving skills and the potential for community contributions through research (Cherwitz, 2005); wide discussion of graduate education, getting a $\mathrm{PhD}$, and what doctoral education is and means (Aspray \& Bernat, 2000; Olson, 1988); summer research opportunities (Jonides, von Hippel, Lerner, \& Biren Nagda, 1992); and the formation of partnerships with minority serving institutions (MSIs) to gain access to a talented pool of students (Aspray \& Bernat, 2000; Pruitt \& Isaac, 1985).

\section{Admission}

Literatures addressing undergraduate and graduate admissions processes appear to focus on similar themes, describing how applications are reviewed and discussing indicators of "merit." At the undergraduate level many colleges and universities employ a holistic review process, where various aspects of a student's application are considered qualitatively. Other institutions - particularly large public universities - employ a more formulaic system of admission, where points are assigned to various components of an application and students exceeding a certain value are accepted (Atkinson, 2004). Graduate admissions committees appear to balance objective (e.g., GRE scores) and subjective (e.g., letters of recommendation) assessments of a student's file. While many committees rely on more objective indicators, subjective judgments can be made about a student's potential as a scholar based on their past research experiences, proposed research agenda, or anecdotes from faculty recommendations (Ward, 2007).

As institutional agents aim to make admissions decisions, they must decide what they value and the best indicators of students" abilities or "merit." In undergraduate admissions, merit is often broadly defined, including both objective measures of academic merit (high school grades and standardized test scores), coupled with nonacademic measures such as sports, volunteerism, artistic pursuits, and other activities (Killgore, 2009). Scholars arguing for increased diversity in graduate education have also touched on merit and how the objective and subjective aspects of a student's application are balanced. While articles and guides recommend various strategies for enhancing success, several acknowledge the vagueness of posted graduate admissions criteria and the rarity of clearly articulated guidelines necessary for acceptance (e.g. Appleby \& Appleby, 
2006; Ward, 2007). Thus, what "merit" in graduate education is and how it is defined is unclear and inconsistent across faculty and programs, at best.

In addition to addressing questions of merit, some have addressed what is considered as admissions decisions are made, suggesting diversity in the graduate student population requires a more holistic recognition of student potential. For example, the GRE scores of underrepresented students, on average, tend to be lower than those of their peers (Pruitt \& Isaac, 1985; Tapia, Lanius, \& Alexander, 2003). This may lead admissions committee members to perceive underrepresented students as less academically skilled than their peers and unable to handle the rigors of graduate school. However, several scholars (Aspray \& Bernat, 2000; Muñoz-Dunbar \& Stanton, 1999; Tapia et al. 2003) reiterate that GRE scores are standardized tests and imperfect predictors of student success in graduate school, particularly for students of color. As such, these scholars recommend that admissions committees place greater emphasis on other indicators of student potential, such as research experience and letters of recommendation, if they aim to increase student diversity.

\section{Yield}

Few scholars have addressed issues concerning yield or the factors that encourage matriculation in to specific academic programs once students are accepted. Kallio's (1995) work on the choice process of graduate students in the United States is one of few and notes that age and increased likelihood of having a spouse may influence how graduate students choose an institution. In many ways, however, the forces which draw undergraduates to specific institutions are salient for graduate students as well. For example, similar to the undergraduate literature (e.g., Astone \& NunezWomack, 1990; Hossler, 1990; Hossler, Braxton, \& Coopersmith, 1989; Perna, 2006), several scholars stress the importance of financial support. Ample financial support is critical to promoting access to graduate education, particularly for those from lower income backgrounds who are hesitant to take on more educational debt (Aspray \& Bernat, 2000; Muñoz-Dunbar \& Stanton, 1999; Olson, 1988; Pruitt \& Isaac, 1985).

\section{Conceptual Framework}

In addition to the literature on graduate student recruitment, this work is framed by Weick's (1976, 1991) work on loose coupling and organizational behavior. Weick highlights how the loosely coupled nature of colleges and universities in the United States make organizational change difficult. Specifically, while academic programs, administrative offices, and student services function in direct response to one another, they are only connected through weak, loose ties. As loosely coupled organizations, departments and programs within United States institutions "are responsive, but each event also preserves its own identity and some evidence of its physical or logical separateness" (Weick, 1976, p. 3). Loose coupling in higher education in the United States often manifests as decentralization, with each college, department, and program having its own employees with highly specialized skills sets, procedures, and policies. In other words, because departments are connected through weak ties, there is a lower probability that they will develop consistent, comprehensive plans or respond in coordinated ways to institutional pressures and problems.

Loose coupling and decentralization may be particularly salient in the case of graduate education and recruitment. Undergraduate students are admitted to college in the United States by central offices of undergraduate admission, which have trained staffs of admission officers. Alternatively, while many campuses have central offices of Graduate Admission or Graduate Education, graduate admissions decisions are often made at the departmental level. At the undergraduate level, attention tends to be focused on institutional process, climate, and fit, while graduate education admissions decisions more often attend to departmental and program-level decisions, func- 
tions, and interactions. For example, Hirt and Muffo (1998) explain that the decentralized nature of graduate education in the United States makes efforts to understand climate difficult; each department and program has its own standards and unique culture. Further, Lovitts and Nelson (2000) note that while graduate students are often drawn to an institution's reputation and prestige when they are deciding where to apply, their campus experiences and likelihood of retention are ultimately more dependent upon departmental-level strengths, weaknesses, and experiences.

It is also important to note that faculty agency and control are particularly important in graduate education and the graduate recruitment process. Professors are central to departmental governance, the key drivers in establishing departmental climate, and engage in the process of reproducing themselves through designing the curricula, policies, and programs (Gumport, 1993; Hirt \& Muffo, 1998). Faculty take primary responsibility in the training of graduate students and generating the next wave of professors, engaging students in a training process that involves close apprentice-like relationships (Austin \& McDaniels, 2006; Gumport, 1993; Lovitts \& Nelson, 2000). As noted above, faculty play a key role in the recruitment process, largely as the primary decision makers in doctoral admissions in the United States. Posselt (2013) posits professors also have valuable roles to play in encouraging the yield of desired populations. In their study of a highly selective American research university, Bersola, Stolzenberg, Fosnacht, and Love (2014) point to the particular importance of faculty contact in the yield of underrepresented minority students.

While central to the recruitment process, it may be difficult to engage faculty in strategies to increase student diversity. Tapia and colleagues (2003) note faculty rarely invest in the diversity of their student body because they perceive it as unrelated to their professional success, which is largely based on scholarly productivity (Tierney \& Bensimon, 1996). The time intensive process associated with graduate student recruitment, particularly outreach, may be consequently unappealing to faculty; therefore, they may be unwilling or unenthusiastic about participating in recruitment efforts.

\section{Methods}

While generally thin, the extant research on graduate student recruitment and how the recruitment process can be leveraged to increase graduate diversity largely focuses on admissions, with less attention to outreach and yield activities. This work considers efforts to increase graduate student diversity through recruitment efforts, examining the potential barriers and institutional strategies that influence access to graduate education for students from racial and ethnic minority groups. We analyze data collected from 14 GDOs to develop a model of graduate student recruitment, clustering the strategies GDOs engage in to increase diversity into a multi-stage process. We then explore the nature of graduate recruitment and how race and diversity are considered throughout this process. Thus, in addition to generating a conceptual model for graduate student recruitment, this study addressed the following questions:

- How do GDOs describe the nature and various stages of the graduate recruitment process?

- How do GDOs understand their role, influence, and ability to draw attention to issues of race and racial diversity within the graduate recruitment process?

Considering our desire to understand the nuances of the graduate recruitment process and how GDOs perceive the ways in which diversity is considered within this process, we implemented a qualitative multi-case study design, where each GDO serves as her or his own bounded system or case (Merriam, 1998). This strategy is particularly appropriate for addressing how and why questions and for examining the process by which a phenomenon takes place (Merriam, 1998; Yin, 2013), allowing for deeper insights regarding the process of graduate student recruitment, how diversity is considered (or not considered) throughout this process, and how GDOs understand 
their roles and try to influence recruitment. Multi-case studies are designed to include data collection and analysis of more than one case, allowing for comparison across cases and enhanced trustworthiness of findings (Bogdan \& Biklen, 1998; Merriam, 1998). Thus, we conducted an exploration of each GDO's organizational context, roles, responsibilities, and experiences with diversity recruitment, and then we engaged in a cross-case comparison. The multi-case study fostered greater analytical insight into how diversity is included and perceived within the context of graduate student recruitment.

\section{Study Participants}

Study participants were all employed at 11 Comprehensive Doctoral with Medical/Veterinary or Comprehensive Doctoral (no medical/veterinary) universities, as defined by the Carnegie Classifications for Graduate Instructional Programs (Carnegie Foundation for the Advancement of Teaching, 2008). All institutions were located in the United States. Participants were recruited from these types of institutions considering our interest in understanding racial and ethnic diversity recruitment in graduate education generally, and doctoral education specifically, in a United States context. Many of these institutions are regarded as having the top graduate programs in their respective fields, producing the next generation of faculty leaders. More detailed information on the characteristics of these universities can be found in Table 1.

Table 1. Demographics of Institutional Sites

\begin{tabular}{|l|l|l|r|r|r|}
\hline Institution Pseudonym & Region & \multicolumn{1}{|c|}{ Control } & $\begin{array}{c}\text { Total } \\
\text { Enrollment }\end{array}$ & $\begin{array}{c}\text { Graduate } \\
\text { Enrollment }^{\mathrm{b}}\end{array}$ \\
\hline Agriculture University & Midwest & Public & $>35,000$ & 11,000 \\
\hline Baron University & West & Private & $<35,000$ & 11,000 \\
\hline Colony University & South & Public & $<35,000$ & 9,000 \\
\hline Crest University & East & Private & $<35,000$ & 16,000 \\
\hline Flagship University & Midwest & Public & $>35,000$ & 15,000 \\
\hline Green University & West & Public & $>35,000$ & 10,000 \\
\hline Land Grant University & Midwest & Public & $>35,000$ & 8,000 & \\
\hline Mid State University & East & Public & $>35,000$ & 6,000 & \\
\hline Riverdale University & East & Public & $<35,000$ & 3,000 & \\
\hline Seaside University & West & Public & $>35,000$ & 12,000 & \\
\hline Tech University & East & Private & $<35,000$ & 6,000 \\
\hline
\end{tabular}

a To protect participants' identities, institutions are characterized as having total enrollments that are either more or less than 35,000 students b To protect participants' identities, the graduate enrollment numbers are rounded to the nearest thousand.

The sample consists of 14 GDOs, and detailed information on participants can be found in Table 2. Eleven participants are women and three are men. In terms of racial and ethnic diversity, 11 participants self-identify as African American, 1 as Latino/Hispanic, and 2 as White (NonHispanic). While all participants self-identify as GDOs (albeit each with different job titles), some are responsible for a particular school or division of their university $(n=5)$, whereas others are responsible for graduate diversity recruitment and/or retention across the entire university $(\mathrm{n}=$ 9). The average amount of time that each participant has worked in diversity recruitment and retention is 10.4 years $(\mathrm{sd}=7.3)$. Participants also have considerable experience working with graduate students, averaging 11.36 years $(\mathrm{sd}=9.4)$ 
Table 2. Demographic Characteristics of Study Participants

\begin{tabular}{|c|c|c|c|c|c|c|c|c|}
\hline Pseudonym & Institution & Sex & Race/Ethnicity & $\begin{array}{l}\text { Highest } \\
\text { Degree }\end{array}$ & $\begin{array}{c}\text { Location of } \\
\text { Position }\end{array}$ & $\begin{array}{c}\text { Years in } \\
\text { Diversity } \\
\text { Work }\end{array}$ & $\begin{array}{c}\text { Years at } \\
\text { Institution }\end{array}$ & $\begin{array}{c}\text { Years working } \\
\text { with Graduate } \\
\text { Students }\end{array}$ \\
\hline Alex Zapata & Green University & $\mathrm{M}$ & Latino/Hispanic & Doctorate & Graduate School & 2 & 18 & 18 \\
\hline Allison Boyd & Riverdale University & $\mathrm{F}$ & African American/Black & Doctorate & Graduate School & 5 & 5 & 7 \\
\hline Amie Folsom & Agriculture University & $\mathrm{F}$ & White & Doctorate & College & 21 & 9 & 4 \\
\hline Craig Smith & Tech University & M & African American/Black & Masters & Graduate School & 5 & 5 & 5 \\
\hline Deborah Hardwick & Seaside University & $\mathrm{F}$ & African American/Black & Doctorate & Graduate School & 1 & 2 & 1 \\
\hline Denise Miller & Colony University & $\mathrm{F}$ & African American/Black & Masters & Vice President & 16 & 3 & 30 \\
\hline Dustin Chase & Land Grant University & M & African American/Black & Masters & Graduate School & 23 & 30 & 23 \\
\hline Elizabeth Stevens & Crest University & $\mathrm{F}$ & African American/Black & Bachelors & College & 15 & 25 & 25 \\
\hline Jessica Hayman & Flagship University & $\mathrm{F}$ & African American/Black & Bachelors & Department & 6 & 7 & 6 \\
\hline Joann Samuelsson & Mid State University & $\mathrm{F}$ & African American/Black & Masters & College & 19 & 9 & 9 \\
\hline Lindsay Danon & Mid State University & $\mathrm{F}$ & African American/Black & Doctorate & Graduate School & 7 & 7 & 1 \\
\hline Malia Lucas & Baron University & $\mathrm{F}$ & African American/Black & Masters & Department & 11 & 4 & 4 \\
\hline Monique Malone & Baron University & $\mathrm{F}$ & African American/Black & Doctorate & College & 4 & 4 & 11 \\
\hline Sam Bailey & Flagship University & $\mathrm{F}$ & White & Doctorate & Graduate School & 10 & 15 & 15 \\
\hline
\end{tabular}

\section{Procedures}

Participants were identified using two sampling methods. First, a purposeful sampling method was implemented based on the assumption that discovering, understanding, and gaining insight requires selection of a sample from which the most can be learned (Merriam, 1998). A balance of geographic and institutional characteristics, including both public and private universities as well as universities from the West, the Midwest, the South, and the East coast, was also considered in selecting potential participants. A small initial group of GDOs were identified by the researchers and invited to participate via email based on past professional experiences with these individuals and knowledge of their professional roles. Then, the principal investigators identified other institutions that had at least one individual responsible for graduate diversity recruitment through our preliminary research of existing graduate diversity programs. These individuals were also contacted via email and invited to participate in the study. The second sampling technique used was snowball sampling (Bogdan \& Biklen, 1998), which is a subset of purposive sampling. Participants were asked to recommend other potential respondents, who were then contacted by the researchers and invited to participate. Institutions employ different graduate diversity recruitment strategies; some have centralized positions in the Graduate School, while others have multiple positions throughout the institution, located in specific colleges and departments (Griffin \& Muniz, 2011). Thus, some GDOs in our sample are employed at the same institutions, referred as potential participants by their colleagues on the same campus.

All participants met individually with a member of the research team. Most of the interviews were conducted via telephone; six were in person. Participants first completed a brief demographic questionnaire inquiring about their background, work experiences, and current responsibilities. They then took part in a semi-structured interview, allowing for uniform inquiry regarding the key questions guiding this study and providing opportunities for open flow conversation (Hammer \& Wildavsky, 1993; Merriam, 1998). The interview protocol addressed a variety of issues, including, but not limited to, their perceptions of the recruitment process at their institutions, their role in recruitment activities, and differences between the undergraduate and graduate recruitment processes. Interviews lasted approximately 60 to 75 minutes, were recorded, and were transcribed verbatim. All participants were assigned pseudonyms to ensure anonymity and were given a $\$ 25$ gift card to thank them for participating. After the interviews, participants were asked to share any recruitment materials they used, including flyers, brochures, and websites. Notes were taken on the information included in recruitment materials, how materials were disseminated, and different forms of recruitment events advertised. Further, institutional demographic data (and, when available, departmental or college level data) were collected from GDOs 
and the Integrated Postsecondary Education Data System (IPEDS) to better understand the context within which the GDOs worked.

\section{Analyses}

Data from the demographic questionnaires were entered into an electronic file using SPSS software. Descriptive statistical analyses were completed to gain a general sense of the sample in terms of their demographic characteristics, level of experience working with graduate students and issues of diversity, and primary work responsibilities. Institutional data and information were reviewed to gain a deeper understanding of campus demographics, graduate student diversity, and organizational structures (e.g., to whom the GDO reported, the college in which the GDO's department was located). Finally, notes on GDO's recruitment materials were reviewed, examining the activities in which GDOs engaged and how these opportunities to learn more about doctoral programs are described.

Institutional, demographic, and recruitment data were used to supplement and triangulate the primary sources of data for this study: the transcripts from participants' interviews. Each member of the research team reviewed interview transcripts to identify recurring patterns and phenomena described by participants in accordance with a grounded theory approach, which allows for the emergence of themes directly from the interview data (Glaser \& Strauss, 1967). Interview data were analyzed consistent with strategies outlined by Corbin and Strauss (2008) and focused on identifying the ways in which diversity manifested throughout the graduate recruitment process. First, each member of the research team read the interviews, individually memoing about their observations of key phenomena emerging from the interviews, as well as the other forms of data collected through the study. The research team then met to discuss our observations, aggregating specific observations into a comprehensive list, as well as determining whether the recruitment process could be understood as a series of stages and identifying a series of themes emerging from the data. In addition to providing evidence supporting the salience emerging patterns, team members actively sought disconfirming evidence and discussed any data that did not fit into perceived patterns and challenged their perceptions.

After these discussions, a coding scheme was developed based on our identification of stages in the recruitment process, role and importance of race and diversity, and other specific phenomena participants described. Conceptually similar codes were clustered together into larger categories. Identified code clusters relevant for this study included GDOs roles and responsibilities, recruitment strategies, institutional factors influencing diversity in graduate education, and institutional issues and emphasis on race and diversity. The codes were then used to organize data collected from the interview transcripts. ATLAS.ti software was used to apply the codes to specific quotations and passages from participants' narratives. Once codes were applied, the ATLAS.ti software was useful in aggregating quotations assigned the same code, facilitating a cross-case comparison, where similarities and differences were examined across participants. Individual codes, as well as groups of codes within the same coding cluster were re-read to confirm and challenge our early perceptions of the themes we identified in the preliminary stages of data analysis.

\section{Findings}

While this study has much to contribute to understanding efforts to increase graduate diversity in institutions in the United States, we acknowledge several limitations. First, as a qualitative study of fourteen individuals across eleven institutions, this work is not intended to be generalizable. Rather, it offers new insights into how a group of GDOs at different institutions are aiming to influence the recruitment process, and more research must be done to determine whether these findings are applicable to other contexts. Women and African Americans are strongly represented within our dataset; therefore, researchers examining these issues in the future may want to in- 
corporate more diverse perspectives to determine whether narratives are consistent for GDOs from other backgrounds. It is also important to note that this study offers only one perspective on efforts to increase diversity through graduate student recruitment; we do not address or include interviews from other institutional leaders or faculty members. Further, we acknowledge this study highlights one way in which institutions aim to increase diversity in their graduate student communities; we do not explore whether and how institutions without GDOs participate in recruitment and cannot attest to whether efforts to increase diversity take a similar form at those institutions. Finally, we acknowledge that this study focuses on diversity and graduate education in the United States context and reflects the organization and governance structure at research universities. While some of the principles may be applicable in other contexts, future work must be done to understand the relationship between systems of governance, administrative roles, and efforts to increase diversity.

Despite these limitations, the data analyzed for this study provide new insights that can inform efforts to increase student diversity within the loosely-coupled system of graduate education. Based on GDOs' accounts, the graduate recruitment process at institutions in the United States appears to follow the three stage process described above, which has yet to be established empirically or formally described in extant literature about graduate education. In the first stage, which we refer to as "outreach," institutional agents encourage students to consider graduate education generally, and their institution specifically. The second stage, "admissions," is when students apply to the institution and their applications are considered by faculty committees. In the final stage, "yield," admitted students are courted by the institution, encouraging them to matriculate to the campus.

Our cross case analysis revealed that there were distinctive aspects to the recruitment process at each individual institution; however much of what GDOs shared in their narratives was consistent. GDOs articulated their perceptions of the ways in which race and diversity were (or were not) considered at various stages of the process, how the nature and organizational structure of graduate education affected their level of influence, as well as variations in their ability to contribute to the different phases of the recruitment process and encourage diversity on their respective campuses, departments, and programs.

\section{Outreach}

GDOs described several strategies each of their campuses employed to encourage a larger, and hopefully more diverse, applicant pool to submit applications, including paying for access to lists of students of color who were interested in graduate school; making campus visits and attending graduate school fairs; hosting summer research programs; inviting talented students to visit the campus for a "preview weekend" before the application deadline; tabling at national conferences; and building relationships with faculty and administrators at institutions across the country. Overall, GDOs viewed their role in outreach as absolutely essential to their work and a key opportunity to infuse consideration of race and diversity in the recruitment process. As Elizabeth Stevens from Crest University notes, "the reason they created my job is that they knew that they had to do something extra to recruit minority students. That was very clear, and it's still clear." As university spokespeople for graduate admissions across departments at a university, GDOs communicated their awareness that building a racially diverse applicant pool was a key lever of influence over which they had some control. Monique Malone articulates the importance of outreach in her role, and states that much of her work aims to "make the application pool as full as it could be so they [faculty] have the most options possible for doing their admissions process."

GDOs perceived themselves as often being one of few university representatives engaged in targeted graduate outreach to underrepresented communities. Monique Malone, whose position was actually to work on diversity issues for her college, described herself as the "university face [for] 
the graduate school," noting that there was no one else to do outreach to students of color. Thus, while recruitment was often decentralized, GDOs could stand in as a university representative. GDOs shared narratives of attending events and speaking to students across disciplines and programs, even when they did not have the most specific information on hand. Elizabeth Stevens, remarked that as the only person doing this work for her graduate school: "I do what I need to do, I do what I want to do, and everyone's happy that I'm doing it, and they [senior administrators] don't have to pay attention to it." In addition to highlighting her commitment to drawing diversity students into the applicant pool, Stevens's comments suggest GDOs saw themselves as providing a needed outreach function to which faculty, departmental representatives, and senior administrators were unlikely to commit time. Few participants could describe concrete, meaningful ways in which faculty or other administrators contributed to efforts to encourage students of color to apply to their programs, instead relying on the work of GDOs to draw these students into the applicant pool.

\section{Admissions}

In comparing GDOs narratives, the most common term used to describe the graduate admissions process was "decentralized." Graduate applications were reviewed by faculty members, and decisions were made at the departmental level. According to GDOs, some departments engaged in a holistic process, considering students' grades, test scores, research potential, and contributions to the community. More often, however, GDOs observed admissions committees emphasizing students' grades, undergraduate institutions, and perhaps mostly, their GRE scores as they made decisions. Dustin Chase was one of several GDOs who expressed some frustration with this tendency, describing his work as "meaningless" unless faculty placed value on diversity and saw students in a holistic way:

You know, you can bring in all the applications you want, but until they [faculty] really look at the total application and understand how important diversity is to the overall university, then you know, I'm just working for myself.

Dustin Chase's comments suggest the work of GDOs like himself is futile unless faculty were really committed to diversity. He could enhance diversity in the applicant pool through his efforts in outreach, but there would be no increases in diversity in the graduate community unless faculty decision-makers were willing to go beyond emphasizing student GRE scores during the admissions phase, which are indicators on which students of color tend to perform less well (Pruitt \& Isaac, 1985; Tapia et al., 2003), considering student potential in a more holistic way.

GDOs freely expressed their frustration with their lack of a direct role in the admissions process at the graduate level; no GDO in our sample had decision-making power in the graduate student admissions process. For example, while Malia Lucas understood how the specificity of graduate education and students' interests in working with a particular professor made graduate admissions hard to centralize and necessitated faculty involvement, she still wished for some "happy medium" between faculty having complete control and trained professionals interceding.

Despite not being able to actually serve on graduate admission committees, the cross-case analysis revealed different strategies GDOs implemented to have more influence on admissions. Six of the GDOs reminded committees of top applicants of color they encountered during outreach activities. Two of these GDOs shared that they appealed directly to admissions committees (Jessica Hayman and Elizabeth Stevens); both were organizationally located at the college and departmental levels of the institution. Jessica Hayman sometimes interjected in the admission process, advocating for candidates with whom she was personally familiar. Elizabeth Stevens did not sit on admission committees, but read applications and would let a department know if she felt a strong minority candidate had been overlooked. She stated, "If there's a top person that I had 
evaluated as someone who's a star, who's not on that list, then I can contact the department and say, 'What's up with this?"' Thus, GDOs, particularly those that were in closer proximity to their faculty organizationally, could take on the role of "advisor" in the admissions process, reminding faculty of the importance of racial diversity and focusing their attention on students of color they may otherwise ignore or overlook.

In addition to advocating for specific students, the remaining four GDOs who worked with faculty had influence by facilitating conversations about best practices in admission and increasing diversity. Malia Lucas and Monique Malone conducted workshops for faculty, discussing the importance of holistic admissions and how to assess student potential beyond what was indicated by standardized test scores. Inquiries from various departments led Craig Smith to bring faculty across campus together for conversations about best practices. Denise Miller was able to provide context for faculty committees as they considered applicants. She noted:

Many times if [applicants] come from a Hispanic Serving Institution or an HBCU [historically Black college or university], the faculty may not be as familiar with that institution, so I try to share with them, how that is viewed in the overall population of graduate schools.

Denise Miller's point highlights her faculty's lack of knowledge about minority serving institutions like Hispanic Serving Institutions and historically Black colleges and universities, which are recognized as producing a disproportionate number of students of color entering graduate school (Lundy-Wagner, Vultaggio, \& Gasman, 2013; Redd, 1998; Solorzano, 1995). Their lack of recognition of these schools can put students of color at a disadvantage in the admissions process, despite their potential as young scholars. Thus, by engaging faculty in conversations and workshops, Denise Miller and others provided faculty with opportunities to gain access to information which would hopefully increase the likelihood of seeing the potential in the applications of students of color.

GDOs from seven of the universities aimed to have influence during the admissions phase by informing graduate departments about funding opportunities available for students who brought some form of diversity to the graduate population. In some cases, GDOs oversaw the distribution of these funds, which provided partial or full doctoral fellowships. Monique Malone described a program through which departments could nominate doctoral applicants for a broadly defined diversity fellowship, allowing departments to make a case for how a candidate brought diversity to their graduate program. Fellowship guidelines encouraged faculty to do more to increase racial diversity in their pool of admitted students. Malone elaborated on the complexity of this process, noting that she wanted to avoid having departments simply expecting her office to fund all students of color that they chose to admit:

The trick there is, of course, not allowing the departments to play the game where they push off all their students [to us]... we kind of solved that by letting them know that the more diverse your admit pool is, the more likely you are to get more money. If there's no one [underrepresented students] in your admitted cohort, you've got to explain to us why we should give you a fellowship...

Alex Zapata described a similar program at his university. Departments could nominate applicants for a diversity fellowship; however, he tried "to remind people, that we are a supplemental service. We don't have the resources, we don't have the capacity to fund as large a percentage of the URM [underrepresented minority] prospective students that become students at the University because of those limitations." Thus, GDOs aimed to not only support students from diverse backgrounds with extra funds, they encouraged faculty to do more in terms of admitting students of color and improving graduate diversity by providing financial incentives. 


\section{Yield}

GDOs spent less time describing institutional yield activities. Much like outreach, multiple strategies were incorporated into yield efforts, including campus visits and special visitation weekends for admitted students, generous financial aid packages, and correspondence from faculty and current students. Specific combinations of strategies varied across institutions, but most incorporated two types of efforts: exposure to campus and financial support. Some institutions hosted weekends for all admitted students of color to visit campus at one time. These programs were viewed as beneficial because they allowed students to meet individuals across campus, building a sense of "critical mass," as well as a connection to both the institution and their individual departments. Others were more decentralized with departments planning their own yield events.

Financial aid appears to be particularly critical to yield efforts, and several GDOs discuss the importance of financial packages in drawing students to their campuses. Dustin Chase clearly notes the importance of funding, explaining that it is as important as other outreach strategies:

You're interested, and you have these visitations, and you have this summer research and you have all this stuff going. But then, when you get admitted, they don't have any money to bring you there. . . we need to have more money to bring in more students.

Denise Miller also highlighted the importance of funding students at levels competitive with what other campuses offered. Alex Zapata expanded on this idea as he discussed the fellowships offered at Green University, noting they have not kept up with inflation and that they were adding "top-off awards" to be more competitive with other institutions.

Financial and exposure efforts were often combined to encourage matriculation. Joann Samuelsson recounted a yield experience with a student, which she described as almost being like a faculty hire. The faculty on her campus really wanted this student to enroll, inviting the student for two campus visits, complete with faculty meetings and dinners, as well as increasing her financial award. While these efforts were ultimately unsuccessful in getting this student to attend the institution, Samuelsson notes that efforts to get the most talented students of color "take that kind of effort."

In addition to coordinating campus visits and helping to negotiate financial offers, GDOs often participated in yield by serving as a resource to students as they engaged in their decision-making processes. GDOs frequently found themselves as key liaisons between the university and admitted students. They saw themselves as people that the applicants were familiar with, to whom they could pose questions ranging from quality of life and racial climate to how to navigate the university. Lindsay Danon noted that students of color often inquired about lifestyle questions as they weighed their enrollment options for graduate school:

You know, we've got the sort of typical, "Where do I get this? How do I get this done? Who do I need to know?" ... Everybody who is new deals with that. I just am not sure everybody is clear that people of color have an extra set of acclimation issues. . . "Am I going to need to be the voice ... for all people of color? Or women?"

Danon spoke with students often about issues related to racial climate and their potential experience on campus and was comfortable in addressing students' questions, often pointing out their proximity to several metropolitan areas and opportunities to build community with other people of color. Deborah Hardwick also was in a position to offer guidance to students as they made their enrollment decisions. Many students she had met during the recruitment process would contact her and ask for help with making their final decision.

Despite the personal yield efforts and coordination of yield activities, GDOs reported that faculty could make the most compelling pitch to students, because the experience of being in graduate 
school ultimately was going to be very localized and decentralized. Sam Bailey, whose position was in the graduate school, reflected that her support would only be so helpful in the yield process and required a more proximal and direct faculty investment. She shared:

You know, I could make students feel wanted and interested and engaged but unless the faculty do that, nobody is going to want to make that move to come here. Now the students know it's my job to recruit them to come here (laughs) but [it's] for the faculty to say, "I think you're the best. I want you to come and work in my lab."

Denise Miller also acknowledged the importance of faculty voice and support during the yield phase, describing her plan to gain greater faculty buy-in and involvement. Her hope was that, "when [faculty] get these applications and interview their students and make the offers, we can get them here. And they have to participate in that." She emphasized that faculty must be involved in the yield process if they were going to be successful in enrolling more students of color.

\section{Conclusion}

In the early 2000 s, approximately $21 \%$ of all doctoral students in the United States were people of color; however, over a third of the United States' population was either Native American, Black, Latina/o, or Asian/Pacific Islander. While there certainly has been some growth in the number of people of color enrolling in graduate programs in the United States, most populations have grown more slowly than the international student population (Sowell, Zhang, Bell, \& Redd, 2008). Considering the lack of change in the graduate student population despite demographic shifts in the population of the United States and increased diversity in the undergraduate population, the active recruitment of students of color is central to increasing diversity in the graduate programs at U.S. universities (Aspray \& Bernat, 2000; Council of Graduate Schools and Educational Testing Service, 2010; Muñoz-Dunbar \& Stanton, 1999; Olson, 1988; Tierney et al., 2004). For many campuses, creating GDO positions to lead student recruitment efforts may serve as an important demonstration of an emerging institutional commitment to racial equity and promoting diversity. Rather than just stating diversity is important, which is characteristic of a superficial commitment (Hurtado, Milem, Clayton-Pederson, \& Allen, 1999), institutional leaders have made more enduring commitments and directed some level of financial resources toward creating a more heterogeneous campus community through the establishment of these positions. Regardless of their level of power or control in the recruitment process generally or the admissions process specifically, it is important to understand these administrators' perspectives given that they are being hired to provide leadership and guidance to institutions, departments, and programs seeking to increase graduate diversity. Thus, this study contributes to the limited research on graduate recruitment, providing valuable insights from the perspective of administrators intimately involved in multiple dimensions of the process.

While institutions may demonstrate their willingness to go beyond diversity rhetoric by creating GDO positions, they also must be mindful that creating a diverse, inclusive environment requires a commitment that is embraced and demonstrated throughout the community. This concentration of responsibility with one individual in an institution, department, or program immediately calls an organization's true level of commitment into question. Change that promotes diversity and inclusion must be addressed by a community rather than one person in one office (Hurtado et al., 1999; Smith 2009), particularly given where they are situated in the organization and their decision making power in the recruitment process. Our findings do not suggest that the role of GDOs were completely unimportant; they created important initiatives, advocated for students, and had some level of influence. GDOs have the potential to play a critical role in coordinating recruitment activities, particularly in the outreach phase, that otherwise might not exist or occur inconsistently. However, others had to be invested at other stages of the recruitment process to truly increase diversity on their respective campuses. Thus, our findings suggest that in addition to 
having key individuals in place to coordinate diversity efforts, a strong contingent of community members must commit to considering diversity as an important issue and goal to promote change.

The findings of this study suggest that the efficacy of many GDOs may be hampered by the nature and structure of graduate education in the United States. While colleges and universities in the United States generally function as loosely coupled systems (Weick, 1976, 1991), graduate education is highly decentralized, with the majority of policies, programs, and student-faculty interactions taking place at the departmental rather than the institutional level (Hirt \& Muffo, 1998; Lovitts \& Nelson, 2000). This study reminds that if progress is to be made in increasing graduate student diversity, the nested nature of colleges and universities must be taken into account. Institutional strategies must be coupled with departmental strategies that resonate with the decentralized nature of graduate education. In other words, institutional leaders must consider how to enable and encourage meaningful participation from both GDOs and faculty members during all three phases of the recruitment process to increase graduate diversity.

The need for a true institution-wide emphasis and commitment to diversity throughout all members of the campus community becomes particularly apparent when attending to the admissions stage of the recruitment process. While critical to outreach and yield, GDOs are often unable to directly impact admission decisions made by faculty committees. The GDOs that were able to have the most influence on this dimension of the recruitment process were those that were located organizationally in closer proximity to their department or program. If faculty are not engaging in a holistic admissions process that considers what students from underrepresented backgrounds can add to their communities and fields of study, efforts channeled toward the outreach and yield stages cannot realize their full potential.

This study also adds to the extant literature by providing an alternative perspective on the graduate school choice process in the United States, contributing to the knowledge regarding how actions by institutional agents and decision-making processes shape institutional choice. The literature related to college choice has been dominated by student-oriented perspectives and has focused on the agency of students and the factors shaping their choices. Alternatively, this study identifies a three-stage recruitment process (outreach, admission, and yield), and enhances scholarly understanding of the different levels of influence institutional agents can have in attracting graduate students, and particularly students of color, to American universities.

When one considers these stages, coupled with GDOs' placement in the institution and the decentralization of graduate recruitment, the scope of GDOs' responsibility is particularly wide and challenging to manage. This study contributes an understanding of GDOs' work and how they engage in each phase of the recruitment process, particularly as they engage issues of racial and ethnic diversity. As noted above, GDOs appear to engage most actively in the outreach phase, creating and facilitating opportunities for prospective students to learn about their university and connect with faculty and current students. GDOs most often describe their challenges with the admissions stage and are relatively unable to directly affect faculty decisions, minimizing their ability to truly influence the number of students of color who could potentially enroll at the university. The admissions process remains under faculty domain, which results in both admissions standards and considerations of diversity varying substantially by department.

Without any guarantee that diversity will be considered within a doctoral admission committee, GDOs observe that the diversity of admitted students varies greatly. Workshops, fellowship opportunities, and levels of personal commitment among faculty can factor positively into efforts to increase diversity within a department's pool of admitted students. Efforts to draw a diverse applicant pool may or may not be fully appreciated by faculty convinced that GRE scores are the most effective measures of merit. Using quantitative measures as indicators of ability and research potential can disadvantage students from underrepresented backgrounds with high poten- 
tial but less academic preparation (Aspray \& Bernat, 2000; Muñoz-Dunbar \& Stanton, 1999; Pruitt \& Isaac, 1985; Tapia, et al., 2003). Thus, rather than increasing student diversity, the status quo is maintained through the use of measures of merit that perpetuate rather than mitigate inequality. In sum, GDOs do important work in drawing a diverse applicant pool, yet their inability to engage directly in the admissions process, coupled with an inconsistent faculty commitment to graduate student diversity and assessments of ability based on metrics which disadvantage students of color, often results in a group of admitted students less diverse than the applicant pools that they worked so hard to attract. Thus, while they are not ineffective, one could say that their efforts are less effective than they would have hoped.

Similar to the comments of a GDO participating in our study, the graduate recruitment process in some ways mimics the faculty recruitment process. Based on GDOs' narratives, the level of departmental fit sought by graduate students may be more similar to the fit sought out by prospective faculty candidates than by prospective undergraduates, who often do not have the same level of disciplinary focus. Faculty investment in the graduate admissions process is also aligned with faculty selection, a process during which faculty select their future peers. Similar to graduate admissions, faculty hiring policies and decisions are made by faculty within departments. The criteria for faculty and graduate selection are similarly vague, less than objective, and subject to faculty perceptions of what constitutes "merit" and "fit" in an applicant (Smith, Turner, OseiKofi, \& Richards, 2004; Tuitt, Danowitz Sagaria, \& Viernes Turner, 2007). There are also similarities in terms of yield. The courtship of admitted graduate students by faculty through individual meetings with department faculty, receptions, and dinners demonstrates a level of faculty investment in the graduate recruitment process that is far less evident in the undergraduate recruitment process and feels more like the courtship experienced by faculty candidates.

Universities that understand the uniqueness of the graduate recruitment process, the ways race and diversity are and are not considered at each stage, as well as how graduate recruitment is similar to the faculty selection may be better situated to increase racial and ethnic diversity within their universities. Demonstrating a commitment to graduate diversity can start with hiring a GDO, but GDOs are limited in their ability to increase diversity in graduate education alone. The level of attention that GDOs can give and their level of influence varies based on their placement in the institution; more departmental and programmatic proximity lends to more influence. Despite the importance of having institutional agents coordinating diversity related efforts, it is far too much for one individual to be responsible for increasing diversity in graduate education for a department or an institution. Substantial change requires an underlying emphasis on and commitment to diversity in graduate education that extends beyond the institutional level to individual departments and programs. Therefore, as institutions worldwide consider strategies to increase diversity on their respective campuses, this study reinforces the importance of attending to organizational structure in identifying potential opportunities for change.

\section{References}

Appleby, D. C., \& Appleby, K. M. (2006). Kisses of death in the graduate school application process. Teaching of Psychology, 33(1), 19-24.

Aspray, W., \& Bernat, A. (2000). Recruitment and retention of underrepresented minority graduate students in computer science. Washington, D.C.: Computing Research Association.

Astone, B., \& Nunez-Womack, E. (1990). Pursuing diversity: Recruiting college minority students. Washington, D.C.: Jossey Bass.

Atkinson, R. C. (2004). Achievement versus aptitude in college admissions. In R. Zwick (Ed.), Rethinking the SAT: The future of standardized testing in university admissions (pp. 15-24). New York, NY: RoutlegeFalmer. 
Austin, A. E., \& McDaniels, M. (2006). Preparing the professoriate of the future: Graduate student socialization for faculty roles. In J. C. Smart (Ed.), Higher education: Handbook of theory and research (Vol. XXI, pp. 397-456). New York, NY: Springer.

Bersola, S. H., Stolzenberg, E. B., Fosnacht, K., \& Love, J. (2014). Understanding admitted doctoral students' institutional choices: Student experiences versus faculty and staff perceptions. American Journal of Education, 120(4), 515-543.

Bogdan, R. C., \& Biklen, S. K. (1998). Qualitative research in education: An introduction to theory and methods (3rd ed.). Boston: Allyn and Bacon.

Carnegie Foundation for the Advancement of Teaching. (2008). Carnegie classification description: Graduate instructional program classification. Retrieved from the Carnegie Foundation for the Advancement of Teaching website: http://classifications.carnegiefoundation.org/descriptions/grad_program.php

Cherwitz, R. A. (2005). Diversifying graduate education: The promise of intellectual entrepreneurship. Journal of Hispanic Higher Education, 4(1), 19-33.

Corbin, J. M., \& Strauss, A. (2008). Basics of qualitative research ( $3^{\text {rd }}$ ed.). Thousand Oaks, CA: Sage Publications.

Council of Graduate Schools. (2009). Broadening participation in graduate education. Washington, D.C.: Author.

Council of Graduate Schools and Educational Testing Service. (2010). The path forward: The future of graduate education in the U.S. Washington, D.C.: Author.

Glaser, B. G., \& Strauss, A. L. (1967). The discovery of grounded theory: Strategies for qualitative research. Chicago: Aldine Publishing.

Griffin, K. A., \& Muniz, M. (2011). The strategies, struggles, and successes of graduate diversity officers (GDOs) in the recruitment of students of color. Equity and Excellence in Education, 44(1), 57-76.

Griffin, K. A., Muniz, M., \& Espinosa, L. (2012). Beyond institutional commitment: Understanding the influence of campus racial climate on efforts to promote diversity in graduate education. The Review of Higher Education, 35(4), 535-566.

Gumport, P. J. (1993). Graduate education and organized research in the United States. In B.R. Clark (Ed.), The research foundations of graduate education: Germany, Britain, France, United States, Japan (pp. 225-260). Los Angeles, CA: University of California Press.

Hammer, D. C., \& Wildavsky, A. (1993). The open-ended, semistructured interview: An (almost) operational guide. In A. Wildavsky (2nd ed.), Craftways: On the organization of scholarly work (pp.57102). New Brunswick, NJ: Transaction.

Hirt, J. B., \& Muffo, J. A. (1998). Graduate students: Institutional climates and disciplinary cultures. New Directions in Institutional Research, 98, 17-33.

Hossler, D. (1990). The role of financial aid in enrollment management. New Directions for Student Services, 89(Spring), 77-90.

Hossler, D., Braxton, J., \& Coopersmith, G. (1989). Understanding student college choice. In J. C. Smart (Ed.), Higher education: Handbook of theory and research (Vol. 5, pp. 231-288). New York: Agathon Press.

Hurtado, S., Milem, J., Clayton-Pedersen, A., \& Allen, W. R. (1999). Enacting diverse learning environments: Improving the climate for racial/ethnic diversity in higher education. Washington, D.C.: ASHE-ERIC Higher Education Report.

Jonides, J., von Hippel, W., Lerner, J. S., \& Biren Nagda, B. (1992, August). Evaluation of minority retention programs: The undergraduate research opportunities program at the University of Michigan. Paper presented at the annual meeting of the American Psychological Association, Washington, D.C.. 
Kallio, R. E. (1995). Factors influencing the college choice decisions of graduate students. Research in Higher Education, 36(1), 109-124.

Killgore, L. (2009). Merit and competition in selective college admission. The Review of Higher Education, 32(4), 469-488.

Lovitts, B. E., \& Nelson, C. (2000). The hidden crisis in graduate education: Attrition from Ph.D. programs. Academe, 86(6), 44-50.

Lundy-Wagner, V., Vultaggio, J., \& Gasman, M. (2013). Preparing underrepresented students of color for doctoral success: The role of undergraduate institutions. International Journal of Doctoral Studies, 8 , 151-172. Retrieved from http://ijds.org/Volume8/IJDSv8p151-172Lundy-Wagner0381.pdf

Merriam, S. B. (1998). Qualitative research and case study applications in education. San Francisco, CA: Jossey-Bass.

Muñoz-Dunbar, R., \& Stanton, A. L. (1999). Ethnic diversity in clinical psychology: Recruitment and admission practices among doctoral programs. Teaching of Psychology, 26, 259-263.

Olson, C. (1988). Recruiting and retaining minority graduate students: A systems perspective. Journal of Negro Education, 57(1), 31-42.

Perna, L. W. (2006). Studying college access and choice: A proposed conceptual model. In J. C. Smart (Ed.), Higher education: Handbook of theory and research (Vol. XXI, pp. 99-157). New York: Springer.

Posselt, J. (2013). The merit - diversity paradox in doctoral admissions: Examining situated judgment in faculty decision making (Unpublished doctoral dissertation). University of Michigan, Michigan.

Pruitt, A. S., \& Isaac, P. D. (1985). Discrimination in recruitment, admission, and retention of minority graduate students. Journal of Negro Education, 54(4), 526-536.

Redd, K. E. (1998). Historically Black colleges and universities: Making a comeback. New Directions for Higher Education, 102, 33-43.

Smith, D. G. (2009). Diversity's promise for higher education: Making it work. Baltimore, MD: Johns Hopkins University Press.

Smith, D. G., Turner, C. S., Osei-Kofi, N., \& Richards, S. (2004). Interrupting the usual: Successful strategies for hiring diverse faculty. The Journal of Higher Education, 75(2), 133-160.

Solorzano, D. G. (1995). The doctorate production and baccalaureate origins of African Americans in the sciences and engineering. Journal of Negro Education, 64, 15-32.

Sowell, R., Zhang, T., Bell, N., \& Redd, K. (2008). Ph.D. completion and attrition: Analysis of baseline demographic data from the Ph.D. completion project. Washington, D.C.: Council of Graduate Schools.

Tapia, R., Lanius, C., \& Alexander, B. (2003). Factors that influence science and engineering graduate student diversity: Results of a Rice faculty survey. Houston, TX: Rice University.

Tierney, W. G., \& Bensimon, E. M. (1996). Promotion and tenure: Community and socialization in academe. New York: State University of New York Press.

Tierney, W. G., Campbell, C. D., \& Sanchez, G. J. (2004). The road ahead: Improving diversity in graduate education. Los Angeles, CA: Center for Higher Education Policy Analysis.

Tuitt, F. A., Danowitz Sagaria, M. A., \& Viernes Turner, C. S. (2007). Signals and strategies in hiring faculty of color. In J. C. Smart (Ed.), Higher education: Handbook of theory and research (Vol. XXII, pp. 497-535). New York: Springer.

Ward, N. (2007). The (un)predictability of computer science graduate school admissions. Communications of the $A C M, 50(3), 104-106$. 
Weick, K. E. (1976). Educational organizations as loosely coupled systems. Administrative Science Quarterly, 21(1), 1-19.

Weick, K. E. (1991). Making sense of the organization. Malden, MA: Blackwell.

Yin, R. K. (2013). Case study research: Design and methods (5th ed.). Thousand Oaks, CA: Sage Publications.

\section{Biographies}

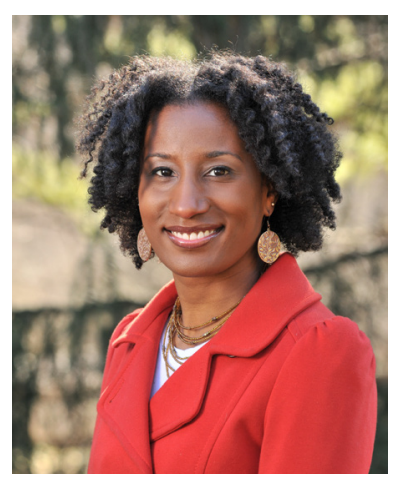

Kimberly A. Griffin is an Associate Professor at the University of Maryland. Prior to becoming a faculty member, she served as a higher education administrator and student affairs professional, working in undergraduate and graduate admissions, promoting diverse and hospitable learning environments, and new student orientation. These professional experiences have greatly informed her work as a scholar, and her research focuses on three core topics: the persistence and success of underserved students; diversity within the Black community; and mentoring and developmental relationships.

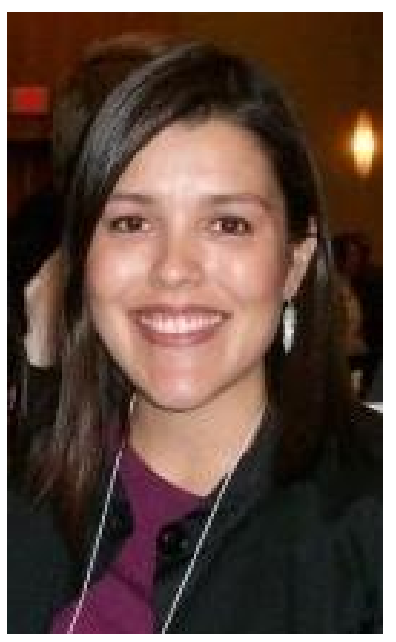

Marcela Muñiz is a scholar specializing in higher education policy and diversity, and a regional director of alumni affairs and development for the Faculty of Arts and Sciences at Harvard University. Prior to completing her doctorate at Stanford University, she spent six years in Undergraduate Admission at Stanford, where she oversaw diversity outreach. Marcela also worked at the United States Department of Education on gender equity and has served on the Stanford in Washington and the National Hispanic Institutes College Register boards. 